\title{
The Perception and Needs of Psychologists Toward Blended Care
}

Citation for published version (APA):

Dijksman, I., Dinant, G-J., \& Spigt, M. (2017). The Perception and Needs of Psychologists Toward

Blended Care. Telemedicine and E-health, 23(12), 983-995. https://doi.org/10.1089/tmj.2017.0031

Document status and date:

Published: 01/12/2017

DOI:

10.1089/tmj.2017.0031

Document Version:

Publisher's PDF, also known as Version of record

Document license:

Taverne

Please check the document version of this publication:

- A submitted manuscript is the version of the article upon submission and before peer-review. There can be important differences between the submitted version and the official published version of record.

People interested in the research are advised to contact the author for the final version of the publication, or visit the DOI to the publisher's website.

- The final author version and the galley proof are versions of the publication after peer review.

- The final published version features the final layout of the paper including the volume, issue and page numbers.

Link to publication

\footnotetext{
General rights rights.

- You may freely distribute the URL identifying the publication in the public portal. please follow below link for the End User Agreement:

www.umlib.nl/taverne-license

Take down policy

If you believe that this document breaches copyright please contact us at:

repository@maastrichtuniversity.nl

providing details and we will investigate your claim.
}

Copyright and moral rights for the publications made accessible in the public portal are retained by the authors and/or other copyright owners and it is a condition of accessing publications that users recognise and abide by the legal requirements associated with these

- Users may download and print one copy of any publication from the public portal for the purpose of private study or research.

- You may not further distribute the material or use it for any profit-making activity or commercial gain

If the publication is distributed under the terms of Article $25 \mathrm{fa}$ of the Dutch Copyright Act, indicated by the "Taverne" license above, 


\section{The Perception and Needs of Psychologists Toward Blended Care}

\author{
les Dijksman, MSc, ${ }^{1}$ Geert-Jan Dinant, $P h D,{ }^{1}$ and Mark Spigt, $P h D^{1,2}$ \\ ${ }^{1}$ Department of Family Medicine, Maastricht University/CAPHRI \\ School for Public Health and Primary Care, Maastricht, \\ The Netherlands. \\ ${ }^{2}$ Department of Community Medicine, General Practice \\ Research Unit, the Arctic University of Norway, Tromsø, Norway.
}

\begin{abstract}
Background: Blended care, meaning that online (Internet) components are used in combination with face-to-face contact, in mental health is increasingly encouraged, but research about the needs of psychologists is scarce.

Methods: We assessed the perceptions, design, and barriers toward blended care among members of the Dutch Association of Psychologists through an e-mailed survey. Mean scores (SD) and answer percentages were calculated. MannWhitney tests were performed to investigate differences between users and nonusers and primary- and secondary care professionals.
\end{abstract}

Results: Generally, psychologists (63\% response rate) had a positive perception toward blended care and they intended to use it in future $(M=3.71, S D=1.19)$. Users of blended care and secondary care professionals were more positive toward blended care than nonusers and primary care professionals. Online psychoeducation, diary forms, and exercises for different therapeutic approaches and communication technology configurations were most welcomed. Still, quite some barriers were mentioned before professionals would use blended care.

Conclusions: Psychologists had a positive perception toward blended care, as long as attention is paid to the perceived barriers. Results of this survey could be used in the development of online components that correspond to the needs of professionals. Reviewing the needs of psychologists, e-health components of different therapeutic approaches, apart from cognitive behavioral therapy, are welcomed. Future research is necessary to gain insight in the (cost) effectiveness of blended care for different types of patients (e.g., transdiagnostic interventions) and of different therapeutic approaches.

Keywords: blended care, e-health, mental health, primary healthcare, secondary care, therapeutics, telemedicine

\section{Introduction}

here has been a steady increase in the use of online self-help programs for mental disorders in the past decade. ${ }^{1-4}$ Usually, it concerns standardized psychological treatments using the Internet, with minimal support from a mental health professional. ${ }^{1,2}$ However, despite the fact that many online treatments have been shown to be effective and efficient, ${ }^{3-5}$ the transition from face-toface contact to online interventions is progressing relatively slowly. ${ }^{6}$ In addition, it has been shown that, although the initial uptake and acceptability of the programs are usually good, dropout rates are high. ${ }^{1,7}$ To overcome these issues, adding faceto-face therapist support to online interventions is proposed. ${ }^{1,5,8}$ Stand-alone online treatment therefore often develops into socalled "blended care", meaning that online components are used in combination with face-to-face contact. ${ }^{9,10}$

Blended care can have advantages such as having more options for self-management, between-session communication between patient and therapist, a more independent patient-therapist relationship, and better preparation of faceto-face sessions. ${ }^{9,11}$ Dutch healthcare policy makers actively encourage this form of treatment and it is expected that blended care will play an increasingly important role in mental healthcare in the coming years. ${ }^{12}$

Despite these high expectations research regarding the perceptions and needs of healthcare professionals is scarce. A study of van der Vaart et al. (2016) showed that primary care professionals would probably use online interventions in the future and that they were moderately enthusiastic about this form of treatment. ${ }^{13}$ Especially nonusers experienced several barriers to use blended care in their practice. The usefulness, the expected effort, and the facilitation in their practice predicted whether they would use such interventions in future. ${ }^{13}$

A different study of van der Vaart et al. showed that secondary care professionals and their patients generally had a more positive perception toward blended care. ${ }^{9}$ Professionals opted for a flexible database instead of a fixed online protocol, to be able to adapt the treatment to the problems and needs of the patients. ${ }^{9}$ Especially practical online components (such as assignments, diaries, and psychoeducation) were considered useful, while face-to-face contact was deemed more appropriate for process-related components (introduction, evaluation, and discussing thoughts and feelings). ${ }^{9}$ 


\section{DIJKSMAN ET AL.}

The available studies on this topic suffered from a low response rate ${ }^{13}$ or had limited external validity due to the selected population (e.g., secondary care only). ${ }^{9}$ The present study therefore aimed for a large response rate among psychologists working in different settings, to study the perceptions and barriers toward blended care. In addition, the goal of the present study was to investigate specific wishes for the way blended care should be designed.

\section{Methods}

\section{RECRUITMENT AND STUDY POPULATION}

Members from the Dutch Association of Psychologists (Nederlands Instituut van Psychologen, [NIP]) were approached for this survey. The Dutch Association of Psychologists is the largest association of psychologists in the Netherlands, where psychologists from all levels in the psychological health sector are registered. Only practicing psychologists in the Dutch province of Limburg who had registered their e-mail address and telephone number were invited for participation. Excluded were occupational psychologists, psychologists working with persons who have an intellectual disability, working in a nursing home, and health professionals outside the Dutch province of Limburg or with missing contact information. Psychologists were first contacted through e-mail. After two weeks, nonresponders were contacted by telephone or again by e-mail to increase the response rate.

\section{QUESTIONNAIRE}

The questionnaire consisted of 27 open and closed questions, see the Appendix. To eliminate ambiguity regarding blended care, a definition was provided based on the study of Wentzel et al. (2016). ${ }^{10}$ The professionals' demographics were assessed first (e.g., age, gender, echelon, and being a blended care user or not). Second, the psychologists' perceptions were assessed. To investigate the perceptions of the professionals, the Diffusion of Innovation Theory of Rogers (2003) was used as a theoretical framework. ${ }^{14}$ According to this theory there are defined categories of perceived characteristics that are essential predictors for the adoption of an innovation, including its relative advantage (perceived efficiency of the innovation in comparison to alternatives), compatibility (degree to which an innovation is compatible with the beliefs and preferences of the healthcare professional), complexity (perceived difficulty to use the innovation), trialability (perceived ability to use the innovation on a trial basis), and observability (the perceived frequency one uses an innovation or knows people who use the innovation).

Carper et al. (2013) developed a questionnaire, based on this theory, to study clinician perceptions of computer-based psychological treatments and added a component future use intentions (likelihood of using the innovation in future). ${ }^{15}$ Our questionnaire was based on the questionnaire of Carper et al. ${ }^{15}$

To reduce the burden to fill in the questionnaire, we selected questions of each category that were suitable for both users and nonusers. Third, based upon earlier research findings, ${ }^{16,17}$ we examined the likelihood of use of different types of online components (e.g., online psychoeducation and online diary forms), communication technology configurations (e.g., using e-mail, video calls, or mobile technology), and possible exercises specifically applied for different therapeutic approaches (e.g., exercises based on Cognitive Behavioral Therapy, positive psychology, or Acceptance and Commitment Therapy). In addition, we investigated the barriers that prevent the use of blended care, based upon other findings of earlier research. ${ }^{6,18,19}$ Finally, professionals could answer to open questions (i.e., whether they had further needs or comments).

\section{DATA ANALYSIS}

Mean scores, standard deviations, and answer percentages were calculated to analyze the perceptions and barriers of mental health professionals toward blended care. Since the assumption of normality and homogeneity of variances was violated on most subscales, Mann-Whitney tests were performed to investigate differences between users versus nonusers and primary- versus secondary care professionals. The answers to the open question were analyzed and arranged into themes, and a typical citation was selected per theme.

\section{Results}

The inclusion process is shown in Figure 1. A total of 109 mental health professionals were invited to participate, 69 responded (response rate $=63 \%$ ). Three professionals were excluded after filling in the questionnaire, since it turned out they did not meet the inclusion criteria after all (e.g., one was working in a nursing home, one worked with persons with an intellectual disability, and one was not a practicing psychologist). The characteristics of the included professionals $(n=66)$ are shown in Table 1. All possible psychological degrees were represented in the survey (i.e., psychologists, healthcare psychologists, psychotherapists, and clinical (neuro) psychologists). Professionals from different settings and working with different types of psychological disorders, such as depressive-, anxiety-, personality-, or developmental disorders responded. However, no psychologists worked in a general practice office. Our responders were mostly experienced professionals, who did not use blended care in their treatment (i.e., $62 \%$ did not use blended care). 


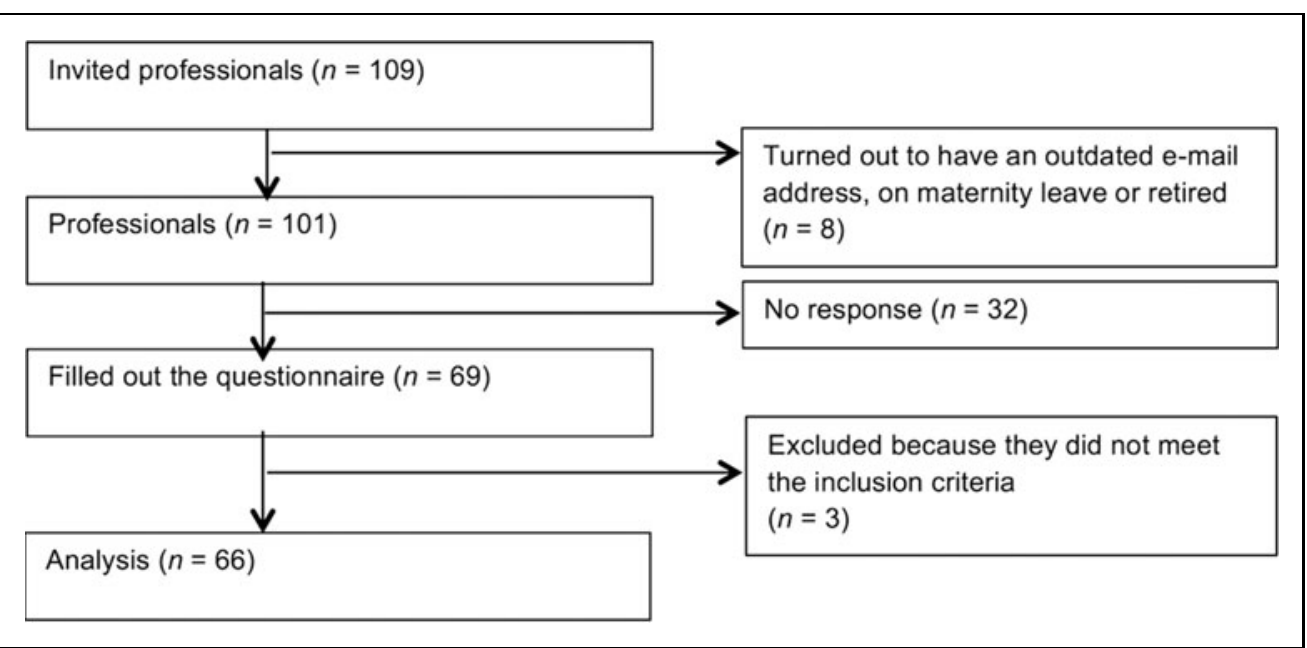

Fig. 1. Flowchart of the included healthcare professionals.

\section{PERCEPTION OF MENTAL HEALTH PROFESSIONALS TOWARD BLENDED CARE}

In general, the professionals had quite a positive perception toward blended care (Table 2). They were rather positive about intended use, compatibility, observability, and complexity. Of note is that $41 \%$ did not try or know where to find a blended care platform (trialability). In total, 30\% did not believe that blended care had a relative advantage (in terms of its effectiveness and expected time savings), compared to treatment as usual.

Additional analyzes showed that users differed significantly from nonusers on all subscales, where users were significantly more positive than nonusers (Table 3). Nevertheless, $44 \%$ of the nonusers believed that they would use blended care in the future. No significant differences were found between primary- and secondary care professionals, except for observability (Table 3). Generally, secondary care professionals scored more positive on the subscales than primary care professionals.

\section{LIKELIHOOD OF USING SPECIFIC TYPES OF ONLINE COMPONENTS IN THE FUTURE}

When looking at the likelihood of using specific online components, it showed that most professionals scored between "neutral and very likely" on all online components, except for the likelihood of using "serious games" in the future (e.g., 39\% did not intend to use serious games in the future), Table 4. Generally, professionals were less likely to use communication technologies such as chat or video, except for using or stay using (secured) e-mail to communicate with patients or colleagues and using mobile technology. Exercises based on mindfulness, cognitive behavioral therapy (CBT),
Acceptance and Commitment Therapy (ACT), and positive psychology were most likely used in the future.

In total 14 persons $(21 \%)$ used the option to report other online components beyond the ones mentioned in the questionnaire (results not shown in the Table). Most notable answers pertained to the need for psychoeducation in different languages than Dutch, modules, exercises, or apps to provide care after a short intensive treatment or when patients are on a waiting list, modules aimed for guiding the elderly, using (diagnostic) questionnaires and token economy systems (e.g., providing positive reinforcement to target behavior change), and using audiotaped relaxation exercises instead of relaxation exercises from screen.

\section{BARRIERS AND NECESSARY PREPARATION ACTIVITIES BEFORE USING A BLENDED CARE PLATFORM}

As shown in Table 5, quite some preparation activities were found to be necessary before using a new blended care program; most scores were rated between "absolutely necessary to neutral", except for the improvement of the computer skills (Table 5). The 3 highest percentage scores were as follows: receiving information regarding the online components (83\% thought this was necessary), followed by knowing the perceptions of the patients (necessary in 79\% of the cases), and the clarification of legal issues/liability (78\% thought this was necessary).

\section{FURTHER COMMENTS REGARDING BLENDED CARE}

A total of 13 respondents answered the general open question at the end of the questionnaire (20\%). The answers could roughly be categorized into four themes as follows: (1) emphasis on using blended care in addition to rather than instead of face-to-face contact, (2) involvement of healthcare insurers and fear of a focus on financial efficiency, (3) limited system flexibility, and (4) suitability for patients. Table 6 presents one illustrative citation per theme.

\section{Discussion}

\section{SUMMARY OF THE MOST IMPORTANT RESULTS}

The aim of the present study was to assess the perceptions and needs of professionals toward blended care. Generally, professionals were positive about blended care and they 
Table 1. Characteristics of Mental Health Professionals $(n=66)$

CHARACTERISTICS

$n=66(\%)$

Gender

\begin{tabular}{l|c}
\hline Male & $24(36 \%)$ \\
\hline Female & $42(64 \%)$ \\
\hline Age $(M, S D)$ & $49(S D=13)$ \\
\cline { 2 - 2 } & Range: $27-83$ years \\
\hline
\end{tabular}

\begin{tabular}{l|c}
\hline \multicolumn{2}{l}{ Professional background } \\
\hline General Psychologist, MSc & $15(22 \%)$ \\
\hline Healthcare psychologist and/or psychotherapist & $38(58 \%)$ \\
\hline Clinical psychologist/Clinical neuropsychologist & $13(20 \%)$ \\
\hline Mean work experience (years SD) & $20(S D=12)$ \\
\cline { 2 - 2 } & Range: 3-52 years \\
\hline
\end{tabular}

Working with

\begin{tabular}{l|c}
\hline Child and adolescents & $8(12 \%)$ \\
\hline Adult care & $57(86 \%)$ \\
\hline Elderly care & $1(2 \%)$ \\
\hline Echelon & $24(37 \%)$ \\
\hline Primary care psychologist (Generalistische Basis GGZ) & $30(45 \%)$ \\
\hline Secondary care (Specialistische GGZ) & $12(18 \%)$ \\
\hline Different (e.g., Medical rehabilitation)
\end{tabular}

General severity of complaints of patient population

\begin{tabular}{l|c}
\hline No mental disorders (subclinical symptoms) & $1(1.5 \%)$ \\
\hline Mild to moderate mental disorders & $29(44 \%)$ \\
\hline Severe to complex mental disorders & $30(45 \%)$ \\
\hline $\begin{array}{l}\text { Guidance in psychiatric department } \\
\text { of a general hospital (very complex care) }\end{array}$ & $1(1.5 \%)$ \\
\hline Different & $5(8 \%)$ \\
\hline Blended care user & $41(62 \%)$ \\
\hline Nonuser & $25(38 \%)$ \\
\hline User &
\end{tabular}

intended to use it in the future. Blended care users and secondary care professionals were more positive toward blended care than nonusers and primary care professionals. Different online components, such as online psychoeducation, diary forms, and exercises of different therapeutic approaches, were most likely used in the future. When looking at the preferred communication technology configurations, especially facili- tation of (secured) e-mail between patients and colleagues and mobile technology, were welcomed. Still, quite some preparation activities were mentioned before professionals would use a new program, such as receiving information regarding the online components, knowing the perceptions of the patients, and the clarification of legal issues/liability. Professionals emphasized on using online components in addition to rather than instead of face-to-face contact. They had concerns about the role of healthcare insurance companies and feared the focus on financial efficiency instead of humanity and patient care.

\section{RESULTS IN RELATION TO LITERATURE, IMPLICATIONS FOR PRACTICE, AND FUTURE RESEARCH}

In line with earlier findings within primary care, ${ }^{13}$ a relatively high amount of professionals planned to use blended care in the future. This could be the result of the fact that healthcare professionals nowadays are highly encouraged by the government and healthcare insurance companies to use this form of treatment. In addition, in correspondence with earlier findings, nonblended care users were less positive toward blended care than blended care users. ${ }^{13}$ The present study not only assessed the perceptions of primary care professionals but also examined and compared the perceptions of professionals in different settings. Generally, no significant differences between primary- and secondary care professionals were found. This might be explained by the fact that the sample size was not large enough to reach statistical significance. Still, it was rather surprising that the secondary care professionals were more positive than primary care professionals, since earlier research showed that Internet-based treatment was more acceptable for patients with mild and moderate symptoms (as seen in primary care) than for patients with severe conditions (as seen in secondary care). ${ }^{18}$ Secondary care psychologists were more positive, for example, about the compatibility and observability. It could be that the online components would better fit to a secondary care setting, where often a more in-depth approach is used instead of a holistic/generalized one.

Results showed that the psychologists were rather positive and had the intention to use different (practical) e-health components in addition to face-to-face contact in future. These results fit within the recommendations of van der Vaart et al., ${ }^{9}$ who found that the complexity of the problems of patients often hinders following a strict protocol, and therefore, a flexible database with practical online components to tailor treatment to patients was suggested. ${ }^{9}$ In the past several years, most developers and researchers focused on online CBT, since CBT is easily structured and, therefore, lends itself to an 


\section{PERCEPTION TOWARD BLENDED CARE}

\begin{tabular}{|c|c|c|c|c|}
\hline SUBSCALE & MEAN (SD) & DISAGREE $^{\mathrm{a}}$ & NEUTRAL ${ }^{b}$ & AGREE $^{\mathrm{c}}$ \\
\hline Relative advantage (Effectiveness and time-saving) & $3.17(0.77)$ & $30 \%$ & $21 \%$ & $49 \%$ \\
\hline Compatibility (Positive perception and fits well with way of delivering therapy) & $3.52(0.94)$ & $24 \%$ & $12 \%$ & $64 \%$ \\
\hline Complexity (Easy to use- and knowing enough about computers to use blended care) & $3.44(0.71)$ & $9 \%$ & $30 \%$ & $61 \%$ \\
\hline Future intentions use (Plan to use blended care in future) & $3.71(1.19)$ & $18 \%$ & $20 \%$ & $62 \%$ \\
\hline Total & $3.38(0.76)$ & $15 \%$ & $38 \%$ & $47 \%$ \\
\hline \multicolumn{5}{|l|}{ Measured on a scale from 1 to 5 ( $1=$ totally disagree to $5=$ totally agree). } \\
\hline \multicolumn{5}{|l|}{${ }^{a}$ Represents a score of $\leq 2.5$. } \\
\hline
\end{tabular}

online format. ${ }^{16,17,20}$ Reviewing the needs of the psychologists developing online components based on different therapeutic approaches apart from CBT, such as exercises based on mindfulness, ACT and positive psychology would be welcomed as well.

During the development of new online components a Center for eHealth Research and Disease Management (CeHRes) roadmap could be used as a holistic framework to improve uptake and impact of the e-health intervention. ${ }^{21}$ The roadmap could be used as a practical approach to plan, coordinate, and execute the development of the e-health intervention using five steps, where stakeholder participation is essential. ${ }^{21}$ The first step (contextual inquiry) includes gathering information from intended users and the environment in which the technology is implemented. ${ }^{21}$ Results of the current study could be used during this step; however, we examined the needs of psychologists only and following this roadmap, information of all important stakeholders should be taken into account. In the design of the components developers could make use of persuasive technologies. ${ }^{22,23}$ For example, a study of Mohr et al. improved adherence rates of a multimodal eMental Health intervention using, among others, a persuasive technology framework in the design of the intervention.

For example, using simple and brief e-health components that involve monitoring and feedback, developing components that can be inserted into daily routine, by making tools that simplify tasks, providing tailored feedback to the patients, using media such as video to promote vicarious learning, and developing specific features that can affect human relationships to improve acceptability of the intervention. ${ }^{23,24}$ Still, in the development and research of blended care there are a lot of interesting and important challenges in the future. ${ }^{16,17} \mathrm{Ob}$ viously, the (cost) effectiveness of blended care needs to be studied and is the focus of a set of future studies. ${ }^{25-27}$ It would be interesting to investigate which types or which parts of blended care are responsible for the effects. ${ }^{16,17}$ In addition, it would be interesting to gain insight in the effectiveness of blended care treatment for different therapeutic approaches apart from CBT and for other disorders besides anxiety- and mood disorders (e.g., treatment of a combination of disorders/ transdiagnostic interventions). ${ }^{16,17}$

Finally, attention should be paid to the barriers of the psychologists that were observed during this study, with the highest scores found for receiving information regarding the online components, knowing the perceptions of the patients, and the clarification of legal issues/liability. In the past years several studies focused on the ethical and legal issues regarding telepsychology. ${ }^{20,28,29-31}$ To meet the psychologists in the need for more clarification about these issues, existing guidelines were developed. ${ }^{30,31}$ These guidelines provide psychologists information about informed consent procedures, standard operating procedures, and emergency issues, necessary to guide and facilitate clinicians in the online provision of mental health services. ${ }^{30}$ To provide guidance for therapists in when and for whom blended treatment could be suitable, therapists could use a Fit For Blended Care instrument that is developed by Wentzel et al. ${ }^{10}$ This instrument assists in a guided dialogue between therapists and patients, discussing possible (practical) prerequisites, barriers (e.g., patients risk of crisis), and facilitators and it provides an advice overview to increase the treatment success. ${ }^{10}$ This information could be provided by the e-health providers, when professionals consider blended 
Table 3. The Perception Toward Blended Care Among Users Versus Nonusers and Primary- Versus Secondary Care Professionals $(n=66)$

\begin{tabular}{|l|l|l|l|l|l|l|l|} 
SUBSCALE & M (SD) & DISAGREE $^{a}$ & NEUTRAL $^{b}$ & AGREE $^{c}$ & $p$-VALUE $^{\mathrm{d}}$ & MDN & $r$
\end{tabular}

Relative advantage (Effectiveness and time-saving)

\begin{tabular}{l|l|l|l|l|l|l|l}
\hline Users & $3.52(0.59)$ & $12 \%$ & $24 \%$ & $64 \%$ & 0.003 & 3.5 & -0.36 \\
\hline Nonusers & $2.96(0.79)$ & $41 \%$ & $20 \%$ & $39 \%$ & & 3.0 \\
\hline Primary care & $3.08(0.83)$ & $33 \%$ & $25 \%$ & $42 \%$ & 0.461 & 3.0 & -0.10 \\
\hline Secondary care & $3.22(0.77)$ & $27 \%$ & $20 \%$ & $53 \%$ & & 3.5 \\
\hline
\end{tabular}

Compatibility (Positive perception and fits well with way of delivering therapy)

\begin{tabular}{l|c|c|c|c|c|c|c}
\hline Users & $4.00(0.69)$ & $4 \%$ & $16 \%$ & $80 \%$ & 0.001 & 4.0 & -0.41 \\
\hline Nonusers & $3.22(0.95)$ & $37 \%$ & $10 \%$ & $53 \%$ & & 3.5 \\
\hline Primary care & $3.25(0.99)$ & $38 \%$ & $8 \%$ & $54 \%$ & 0.259 & 3.5 & -0.16 \\
\hline Secondary care & $3.60(0.90)$ & $17 \%$ & $17 \%$ & $66 \%$ & & 4.0 \\
\hline
\end{tabular}

Complexity (Easy to use and knowing enough about computers to use blended care)

\begin{tabular}{l|c|c|c|c|c|c|c}
\hline Users & $3.80(0.54)$ & $0 \%$ & $20 \%$ & $80 \%$ & 0.001 & 4.0 & -0.41 \\
\hline Nonusers & $3.22(0.72)$ & $15 \%$ & $37 \%$ & $48 \%$ & 3.0 & \\
\hline Primary care & $3.38(0.85)$ & $17 \%$ & $13 \%$ & $70 \%$ & 0.635 & 3.5 & -0.07 \\
\hline Secondary care & $3.38(0.65)$ & $7 \%$ & $47 \%$ & $46 \%$ & & 3.0 \\
\hline
\end{tabular}

Observability (Knowing people/colleagues using blended care)

\begin{tabular}{|c|c|c|c|c|c|c|c|}
\hline Users & $4.14(0.78)$ & $4 \%$ & $8 \%$ & $88 \%$ & 0.000 & 4.0 & -0.46 \\
\hline Nonusers & $3.04(1.19)$ & $39 \%$ & $12 \%$ & $49 \%$ & & 3.0 & \\
\hline Primary care & $3.21(1.20)$ & $29 \%$ & $8 \%$ & $63 \%$ & 0.046 & 3.5 & -0.27 \\
\hline Secondary care & $3.77(1.23)$ & $20 \%$ & $7 \%$ & $73 \%$ & & 4.0 & \\
\hline \multicolumn{8}{|c|}{ Trialability (Tried blended care or know where to find a program) } \\
\hline Users & $4.02(0.82)$ & $4 \%$ & $24 \%$ & $72 \%$ & 0.000 & 4.0 & -0.69 \\
\hline Nonusers & $2.32(0.91)$ & $63 \%$ & $25 \%$ & $12 \%$ & & 2.0 & \\
\hline Primary care & $2.81(1.03)$ & $42 \%$ & $29 \%$ & $29 \%$ & 0.099 & 3.0 & -0.23 \\
\hline Secondary care & $3.37(1.29)$ & $30 \%$ & $20 \%$ & $50 \%$ & & 3.25 & \\
\hline \multicolumn{8}{|c|}{ Future intention use (Plan to use blended care in future) } \\
\hline Users & $4.52(0.77)$ & $4 \%$ & $4 \%$ & $92 \%$ & 0.000 & 5.0 & -0.56 \\
\hline Nonusers & $3.22(1.13)$ & $27 \%$ & $29 \%$ & $44 \%$ & & 3.0 & \\
\hline Primary care & $3.54(1.29)$ & $25 \%$ & $13 \%$ & $62 \%$ & 0.404 & 4.0 & -0.11 \\
\hline Secondary care & $3.80(1.27)$ & $20 \%$ & $20 \%$ & $60 \%$ & & 4.0 & \\
\hline \multicolumn{8}{|l|}{ Total } \\
\hline Users & $4.00(0.43)$ & $0 \%$ & $16 \%$ & $84 \%$ & 0.000 & 4.08 & -0.67 \\
\hline Nonusers & $3.00(0.66)$ & $25 \%$ & $51 \%$ & $24 \%$ & & 2.92 & \\
\hline Primary care & $3.21(0.80)$ & $21 \%$ & $33 \%$ & $46 \%$ & 0.161 & 3.38 & -0.19 \\
\hline Secondary care & $3.52(0.81)$ & $17 \%$ & $30 \%$ & $53 \%$ & & 3.67 & \\
\hline
\end{tabular}

Rated on a scale from 1 to 5 ( $1=$ totally disagree to 5 totally agree).

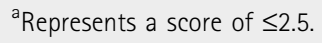

${ }^{\text {bScore }}>2.5$ or $<3.5$.

'Score of $\geq 3.5$.

${ }^{\mathrm{d}}$ Mann-Whitney test to investigate differences between users versus nonusers and primary versus secondary care professionals. 
Table 4. Intention to Use Online Components in Future $(n=66)$

\section{\begin{tabular}{l|l|l|l}
\hline MEAN (SD) & UNLIKELY $^{\mathrm{a}}$ & NEUTRAL $^{\mathrm{b}}$ & LIKELYc $^{c}$
\end{tabular}}

Types of online components

\begin{tabular}{|c|c|c|c|c|}
\hline Online exercises (e.g., exercises for cognitive behavioral therapy or mindfulness) & $3.92(0.97)$ & $9 \%$ & $18 \%$ & $73 \%$ \\
\hline $\begin{array}{l}\text { Online modules (e.g., module depression or anxiety: modules often consist } \\
\text { of psychoeducation and several exercises) }\end{array}$ & $3.41(1.30)$ & $30 \%$ & $8 \%$ & $62 \%$ \\
\hline Serious games (computer games containing a treatment element) & $2.95(1.22)$ & $39 \%$ & $26 \%$ & $35 \%$ \\
\hline \multicolumn{5}{|l|}{ Communication technology configurations } \\
\hline Communicate with patient or colleagues through (secured) e-mail & $3.98(0.98)$ & $9 \%$ & $8 \%$ & $83 \%$ \\
\hline $\begin{array}{l}\text { Mobile technology using sms or app (e.g., by measuring mood/behavior } \\
\text { in the natural environment and moment itself) }\end{array}$ & $3.33(1.22)$ & $27 \%$ & $20 \%$ & $53 \%$ \\
\hline \multicolumn{5}{|l|}{ Possible exercises applied specifically for different therapeutic approaches } \\
\hline Mindfulness exercises & $3.89(0.99)$ & $14 \%$ & $9 \%$ & $77 \%$ \\
\hline Exercises based on cognitive behavioral therapy (CBT) & $3.92(1.04)$ & $9 \%$ & $17 \%$ & $74 \%$ \\
\hline Exercises from the Acceptance and Commitment Therapy (ACT) & $3.71(1.13)$ & $17 \%$ & $18 \%$ & $65 \%$ \\
\hline Exercises based on positive psychology & $3.59(1.20)$ & $23 \%$ & $14 \%$ & $63 \%$ \\
\hline Exercises based on schema therapy & $3.26(1.03)$ & $27 \%$ & $26 \%$ & $47 \%$ \\
\hline Exercises based on interpersonal therapy & $3.05(1.09)$ & $30 \%$ & $29 \%$ & $41 \%$ \\
\hline
\end{tabular}

Measured on a scale from 1 to 5 ( $1=$ very unlikely to $5=$ very likely).

${ }^{a}$ Represents a score of $\leq 2$.

${ }^{\text {bScore }}=3$.

'Score of $\geq 4$.

${ }^{\mathrm{d} S}$ core of $\leq 2.5$ is unlikely, a score $>2.5$ or $<3.5$ is neutral, and a score of $\geq 3.5$ is likely.

care or the information could be made available during trainings to the professionals.

\section{STRENGTHS AND LIMITATIONS}

Studies among healthcare professionals often suffer from very low response rates. The response rate in this study was high (63\%) increasing the chance of having a representative research population. However, practice nurses (PNs) specialized in mental healthcare and working in a general practice office were underrepresented. Van der Vaart et al., ${ }^{13}$ investi- gated the perceptions of PNs and showed that they were more positive than primary care psychologists. Therefore, we expect that our observed general positive perception toward blended care would also apply if we had included more PNs. Second, up until now, there is limited amount of research available that focus on the perceptions of mental health professionals toward blended care. ${ }^{9,13}$ To our knowledge, all available studies were conducted in the Netherlands.

Therefore, one may wonder whether the general positive perception of professionals toward blended care could be 


\section{DIJKSMAN ET AL.}

\begin{tabular}{|c|c|c|c|c|}
\hline BARRIERS & MEAN (SD) & NOT NECESSARY ${ }^{\mathrm{a}}$ & NEUTRAL ${ }^{b}$ & NECESSARYc \\
\hline Obtaining information on online components & $1.95(0.89)$ & $8 \%$ & $9 \%$ & $83 \%$ \\
\hline Determine perceptions patients & $1.95(0.96)$ & $6 \%$ & $15 \%$ & $79 \%$ \\
\hline Clarify legal issues/liability & $2.11(0.85)$ & $8 \%$ & $14 \%$ & $78 \%$ \\
\hline Obtaining information effectiveness platform & $2.12(0.98)$ & $13 \%$ & $12 \%$ & $75 \%$ \\
\hline Determine impact time investment & $2.17(0.91)$ & $8 \%$ & $18 \%$ & $74 \%$ \\
\hline Determine associated incomes and costs & $2.29(1.04)$ & $12 \%$ & $17 \%$ & $71 \%$ \\
\hline Providing more secure network & $2.18(0.90)$ & $8 \%$ & $23 \%$ & $69 \%$ \\
\hline Gather information on existing ethical/clinical guidelines & $2.25(0.83)$ & $5 \%$ & $26 \%$ & $69 \%$ \\
\hline Follow training use platform & $2.43(1.02)$ & $15 \%$ & $26 \%$ & $59 \%$ \\
\hline Ascertain whether care organization agrees to use platform & $2.77(1.41)$ & $28 \%$ & $23 \%$ & $49 \%$ \\
\hline Arranging better IT support & $2.88(1.26)$ & $35 \%$ & $22 \%$ & $43 \%$ \\
\hline Improve computer skills & $3.32(1.16)$ & $46 \%$ & $31 \%$ & $23 \%$ \\
\hline Total $^{d}$ & $2.37(0.65)$ & $5 \%$ & $32 \%$ & $63 \%$ \\
\hline
\end{tabular}

Measured on a scale from 1 to $5(1=$ absolutely necessary $5=$ absolutely not necessary), the total number is lower than 66 due to the missing values of one person.

${ }^{a}$ Represents a score $\geq 4$.

${ }^{\mathrm{b}} \mathrm{S}$ core $=3$.

'Score $\leq 2$.

${ }^{\mathrm{d} A}$ score $\geq 3.5$ is not necessary, a score $>2.5$ or $<3.5$ is neutral, and a score $\leq 2.5$ is necessary.

generalized across countries. Literature shows that many factors influence the professionals' acceptance of e-health applications. ${ }^{32,33}$ Technical conditions, legal contexts, and health policy issues differ per country and seem to play an important role in the use of e-health services. ${ }^{33}$ In addition, with an increased focus on self-management and a more independent therapist-patient relationship, blended care will have an influence on the fit within the patient-therapist interaction, which is considered as one of the essential factors for successful embedded e-health initiatives into routine care. ${ }^{34}$ In the Netherlands, the technical conditions are good; the Internet is frequently used; and e-health technology is highly accessible within the practices. ${ }^{13}$ Blended care would also fit within the patient-professional interactions and it is highly stimulated by government and healthcare insurance companies.

\section{Table 6. Most Notable Comments Regarding Blended Care}

\begin{tabular}{|c|c|c|}
\hline CATEGORY & $\begin{array}{l}\text { NUMBER OF } \\
\text { PROFESSIONALS }\end{array}$ & ILLUSTRATIVE CITATION \\
\hline $\begin{array}{l}\text { Emphasis using blended care in addition } \\
\text { to- rather than instead of face-to-face } \\
\text { contact }\end{array}$ & 4 & $\begin{array}{l}\text { "...Very satisfied using e-health especially for support/in addition to face-to-face treatment. } \\
\text { It cannot completely replace face-to-face treatment in my opinion. It can be useful } \\
\text { to provide exercises, planning, work out schedules, readings etc. at home." }\end{array}$ \\
\hline $\begin{array}{l}\text { Involvement healthcare insurers and fear } \\
\text { of focus on financial efficiency }\end{array}$ & 3 & $\begin{array}{l}\text { "...The healthcare insurers and government have a bad reputation nowadays when it comes to } \\
\text { patient care and humanity versus management and (financial) efficiency." }\end{array}$ \\
\hline Limited system flexibility & 1 & $\begin{array}{l}\text { "...In my quest for blended care providers I encounter limited amount of flexible modules, } \\
\text { where I have to connect to an (expensive) software system, where not all important modules are } \\
\text { integrated (for me)." }\end{array}$ \\
\hline Suitability patient & 1 & $\begin{array}{l}\text { "...l also notice that not every patient (especially depending on the nature of psychological } \\
\text { problems) is open minded to this form of treatment." }\end{array}$ \\
\hline
\end{tabular}




\section{PERCEPTION TOWARD BLENDED CARE}

It is questionable, however, whether the professionals in different countries (e.g., more traditional countries or counties with less Internet access) would be open minded to this form of treatment. Third, despite our large response rate the number of participants was quite small. This was especially a problem for the comparison between different groups, such as echelon differences or differences between different types of patients, and therefore, the latter was not assessed in this study. We expect that with more participants, significant differences between primary- and secondary care users would be found. Finally, it should be noticed that we mostly examined intended behavior, which could differ from actual behavior. It could be that professionals had difficulty in imagining how blended care and the proposed elements would look like or what the possibilities are. ${ }^{9}$ This could also explain the less positive perceptions toward blended care of nonblended care users in comparison to blended care users.

\section{Conclusions}

This study showed that professionals from different healthcare settings had a positive perception toward blended care, as long as the online components were used in addition to rather than instead of face-to-face treatment and attention is paid to the barriers that prevent the use of blended care. The results of this survey could be particularly useful in the development of online programs that would correspond to the needs of psychologists. For example, while in the past years online CBT programs were mainly developed and evaluated, psychologists also opt for development of online components of different therapeutic approaches, apart from CBT. To help professionals in using blended care, more information about the online components, perceptions of the patients, and legal issues/liability must be provided by e-health providers. Further research is necessary to gain insight in the effectiveness of blended care for different types of patients and different therapeutic approaches.

\section{Acknowledgments}

We would like to thank the psychologists of the Dutch Association of Psychologists that participated in this survey for their time and effort during the online survey.

TelePsy, an e-Mental healthcare institution in the Netherlands, funded this study by allowing ID to do the research. Maastricht University paid for the research time for M.S. and G.D.

\section{Ethical Approval}

According to the Dutch law, Medical Research Involving Human Subjects Act (WMO), formal ethical review is not required when participants are not subject to procedures or re- quired to follow rules of behavior. ${ }^{35}$ Therefore, no ethical approval was acquired for this online survey.

\section{Disclosure Statement}

I.D. has a part-time position as a Research and Development Manager at TelePsy and a part-time position as an external $\mathrm{PhD}$ student at Maastricht University.

\section{REFERENCES}

1. de Graaf LE, Huibers MJ, Riper H, Gerhards SA, Arntz A. Use and acceptability of unsupported online computerized cognitive behavioral therapy for depression and associations with clinical outcome. J Affect Disord 2009;116:227-231.

2. Proudfoot J, Goldberg D, Mann A, Everitt B, Marks I, Gray JA. Computerized, interactive, multimedia cognitive-behavioural program for anxiety and depression in general practice. Psychol Med 2003;33:217-227.

3. Richards D, Richardson T. Computer-based psychological treatments for depression: A systematic review and meta-analysis. Clin Psychol Rev 2012;32:329-342.

4. Newman MG, Szkodny LE, Llera SJ, Przeworski A. A review of technologyassisted self-help and minimal contact therapies for anxiety and depression: Is human contact necessary for therapeutic efficacy? Clin Psychol Rev 2011;31:89-103.

5. Spek V, Cuijpers P, Nyklicek I, Riper H, Keyzer J, Pop V. Internet-based cognitive behaviour therapy for symptoms of depression and anxiety: A meta-analysis. Psychol Med 2007;37:319-328.

6. Whitfield G, Williams C. If the Evidence Is So Good - Why Doesn't Anyone Use Them? A National Survey of the Use of Computerized Cognitive Behaviour Therapy. Behav Cogn Psychother 2004;32:57-65.

7. Waller R, Gilbody S. Barriers to the uptake of computerized cognitive behavioural therapy: A systematic review of the quantitative and qualitative evidence. Psychol Med 2009;39:705-712

8. Gerhards SA, Abma TA, Arntz A, De Graaf LE, Evers SM, Huibers MJ, et al. Improving adherence and effectiveness of computerised cognitive behavioural therapy without support for depression: A qualitative study on patient experiences. J Affect Disord 2011;129:117-125

9. van der Vaart $R$, Witting M, Riper $H$, Kooistra L, Bohlmeijer ET, van GemertPijnen $\amalg$. Blending online therapy into regular face-to-face therapy for depression: Content, ratio and preconditions according to patients and therapists using a Delphi study. BMC Psychiatry 2014;14:355.

10. Wentzel J, van der Vaart R, Bohlmeijer ET, van Gemert-Pijnen JE. Mixing Online and Face-to-Face Therapy: How to Benefit From Blended Care in Mental Health Care. JMIR Ment Health 2016;3:e9.

11. Månsson KN, Ruiz ES, Gervind $E$, Dahlin $M$, Andersson G. Development and initial evaluation of an Internet-based support system for face-to-face cognitive behavior therapy: A proof of concept study. J Med Internet Res 2013;15:e280.

12. Schalken $F$, Blankers $M$, Donker $T$, Duinstra $U$, van Gemert $M$, van Hoogenhuyze

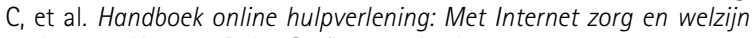
verbeteren. Houten: Bohn Stafleu van Loghum, 2013.

13. van der Vaart $R$, Atema $V$, Evers AW. Guided online self-management interventions in primary care: A survey on use, facilitators, and barriers. BMC Fam Pract 2016;17:27.

14. Rogers EM. Diffusion of innovations (5th ed.). New York: Free Press, 2003.

15. Carper MM, McHugh RK, Barlow DH. The dissemination of computer-based psychological treatment: A preliminary analysis of patient and clinician perceptions. Admin Policy Ment Health 2013;40:87-95.

16. Thewissen V, Gunther N. E-mental health: State of the art. Tijdschrift voor Psychotherapie 2015;41:374-392. 
17. Blankers M, Donker T, Riper H. E-mental health in Nederland: Wetenschappelijke evidentie en uitdagingen voor de praktijk. De Psycholoog 2013;48:12-23.

18. Gun SY, Titov N, Andrews G. Acceptability of Internet treatment of anxiety and depression. Australas Psychiatry 2011;19:259-264.

19. Wells M, Mitchell KJ, Finkelhor D, Becker-Blease KA. Online mental health treatment: Concerns and considerations. Cyberpsychol Behav 2007;10:453-459.

20. Proudfoot JG. Computer-based treatment for anxiety and depression: Is it feasible? Is it effective? Neurosci Biobehav Rev 2004;28:353-363.

21. van Gemert-Pijnen JE, Nijland N, van Limburg M, Ossebaard HC, Kelders SM, Eysenbach $\mathrm{G}$, et al. A holistic framework to improve the uptake and impact of eHealth technologies. J Med Internet Res 2011;13:e111.

22. Oinas-Kukkonen $H_{1}$ Harjumaa M. Persuasive systems design: Key issues, process model, and system features. Commun Assoc Inf Syst 2009;24:28.

23. Fogg BJ. Persuasive technology: Using computers to change what we think and do. Boston: Morgan Kaufmann Publishers, 2003.

24. Mohr DC, Duffecy J, Jin L, Ludman EJ, Lewis A, Begale M, et al. Multimodal e-mental health treatment for depression: A feasibility trial. J Med Internet Res 2010;12:e48.

25. Kooistra LC, Wiersma JE, Ruwaard J, van Oppen P, Smit F, Lokkerbol J, et al. Blended vs. face-to-face cognitive behavioural treatment for major depression in specialized mental health care: Study protocol of a randomized controlled cost-effectiveness trial. BMC Psychiatry 2014;14:290.

26. Romijn G, Riper H, Kok R, Donker T, Goorden M, van Roijen LH, et al. Costeffectiveness of blended vs. face-to-face cognitive behavioural therapy for severe anxiety disorders: Study protocol of a randomized controlled trial. BMC Psychiatry 2015;15:311.

27. Kemmeren LL, van Schaik DJ, Riper H, Kleiboer AM, Bosmans JE, Smit JH. Effectiveness of blended depression treatment for adults in specialised mental healthcare: Study protocol for a randomised controlled trial. BMC Psychiatry 2016;16:113.

28. Childress CA. Ethical issues in providing online psychotherapeutic interventions. J Med Internet Res 2000;2:e5.

29. Baker DC, Bufka LF. Preparing for the telehealth world: Navigating legal, regulatory, reimbursement, and ethical issues in an electronic age. Prof Psychol Res Pract 2011;42:405.
30. Hsiung RC. Suggested principles of professional ethics for the online provision of mental health services. Stud Health Technol Inform 2001; 84:1296-1300.

31. American Psychological Association. Guidelines for the practice of telepsychology. Am Psychol 2013;68:791-800.

32. Li J, Talaei-Khoei A, Seale H, Ray P, Macintyre CR. Health care provider adoption of eHealth: Systematic literature review. Interact J Med Res $2013 ; 2:$ e7

33. Santana S, Lausen B, Bujnowska-Fedak M, Chronaki C, Kummervold PE, Rasmussen J, et al. Online communication between doctors and patients in Europe: Status and perspectives. J Med Internet Res 2010; $12: e 20$.

34. Murray $E$, Burns J, May $C$, Finch $T, O^{\prime}$ Donnell $C$, Wallace $P$, et al. Why is it difficult to implement e-health initiatives? A qualitative study. Implement $\mathrm{Sci}$ $2011 ; 6: 6$.

35. Central Committee on Research Involving Human Subjects (CCMO). www.ccmo.nl/en/your-research-does-it-fall-under-the-wmo. Available at www.webcitation.org/6nuA6jRNr (last accessed May 15, 2017)

Address correspondence to:

Mark Spigt, PhD

Department of Family Medicine

Maastricht University/CAPHRI School for Public Health and Primary Care

PO Box 616

Maastricht $6200 \mathrm{MD}$

The Netherlands

E-mail: m.spigt@maastrichtuniversity.nl

Received: February 6, 2017

Revised: March 20, 2017

Accepted: March 21, 2017

Online Publication Date: May 30, 2017

\section{Appendix}

\section{QUESTIONNAIRE NEEDS OF HEALTHCARE PROFESSIONALS REGARDING BLENDED CARE}

This questionnaire was originally administered in Dutch and translated in English for the publication of the article. It is not formally translated according to standard procedures.

1. Are you currently guiding or treating patients with psychological problems?

- Yes

- No

2. What is your professional background?

- Psychologist in training

- General Psychologist, MSc

- Psychotherapist

- Healthcare psychologist

- Clinical psychologist/Clinical neuropsychologist

- Different, please provide further explanation

3. What is your sex?

- Male

- Female 


\section{PERCEPTION TOWARD BLENDED CARE}

4. What is your age?

5. In what kind of echelon are you mainly working (if you work in different echelons please select the echelon where you are mainly active).

- General practice with practice nurse specialized in mental healthcare

- Primary mental healthcare [in Dutch: Generalistische basis GGZ]

- Specialized mental healthcare [in Dutch: Specialistische GGZ]

- Different (please provide further explanation)

6. How much working experience do you have within mental healthcare?

7. With what kind of patients do you mainly work (if you are working with different patients please select the main patient population)

- Child and adolescents

- Adult care

- Elderly care

- Different, please provide further explanation

8. The patients within your practice/institution mainly have:

- No psychological disorders (subclinical symptoms)

- Mild to moderate psychological disorders

- Severe to complex psychological disorders

- Crisis/residential care (very complex care)

- Different, please provide further explanation

9. What kind of psychological disorders do your patients mainly have?

In this study blended care refers to a combination of face-to-face consultations and online components, where the online components and face-to-face consultations both are not stand-alone treatment pathways but are interconnected to each other. The online components are carefully selected and adjusted to treatment. The online components can be used flexibly and in a dynamic way. The patient and therapist decide together how the online components could be used optimally.

Imagine, for example, a database where you can flexibly select psychoeducation, diary forms, modules, or online exercises (e.g., from cognitive behavioral therapy, Acceptance and Commitment Therapy or meditation exercises) in addition to treatment.

10. Do you use blended care for the treatment/guidance of your patients?

- Yes

- No (little or not at all)

11. Please answer the questions below based on your beliefs about blended care. If you have not heard of blended care before now, base your answers on what you expect to be true.

- Using blended care would save me more time than other treatments

Totally disagree, disagree, neutral, agree, totally agree

- I think that blended care would be effective for a lot of my patients

Totally disagree, disagree, neutral, agree, totally agree

- I have a positive perception about blended care

Totally disagree, disagree, neutral, agree, totally agree

- I believe that blended care would fit with the way I would like to deliver treatment

Totally disagree, disagree, neutral, agree, totally agree

- I think it is easy to use blended care for my patients

Totally disagree, disagree, neutral, agree, totally agree

- I know enough about computers to use blended care

Totally disagree, disagree, neutral, agree, totally agree 


\section{DIJKSMAN ET AL.}

12. Please answer the questions below based on your beliefs about blended care. If you have not heard of blended care before now, base your answers on what you expect to be true.

- I know colleagues who have considered to use blended care

Totally disagree, disagree, neutral, agree, totally agree

- I know people who use blended care

Totally disagree, disagree, neutral, agree, totally agree

- I plan to use/stay using blended care in future for my patients

Totally disagree, disagree, neutral, agree, totally agree

- I have tried blended care

Totally disagree, disagree, neutral, agree, totally agree

- I know where to find online components to try blended care

Totally disagree, disagree, neutral, agree, totally agree

13. Imagine that you are going to work with a new blended care platform, where you can work with the following e-health configurations. How likely would you use the following configurations in addition to face-to-face treatment?

- Online psychoeducation (using text or video)

Very unlikely, unlikely, neutral, likely, very likely

- Online dairy forms (e.g., for tracking thoughts or daily activities)

Very unlikely, unlikely, neutral, likely, very likely

- Online exercises (e.g., exercises based on cognitive behavioral therapy or mindfulness)

Very unlikely, unlikely, neutral, likely, very likely

- Online module (e.g., module depression or anxiety: modules often consist of psychoeducation and different assignments)

Very unlikely, unlikely, neutral, likely, very likely

- Serious games (computer games with a treatment element)

Very unlikely, unlikely, neutral, likely, very likely

14. Are there, apart from the abovementioned components, other components that you as a healthcare professional would need?

- No

- Yes, please provide further explanation

15. Imagine that you are going to work with a new blended care platform, where you can work with the following communication technology configurations. How likely would you use the following technologies in addition to regular face-to-face treatment?

- Communicate with patient or colleagues through chat

Very unlikely, unlikely, neutral, likely, very likely

- Communicate with patient or colleagues through (secured) e-mail.

Very unlikely, unlikely, neutral, likely, very likely

- Communicate with patient or colleagues through video calls

Very unlikely, unlikely, neutral, likely, very likely

- Mobile technology using sms or app (e.g., by measuring the mood/behavior in the natural environment or at the moment itself).

Very unlikely, unlikely, neutral, likely, very likely

16. Imagine that you are going to work with a new blended care platform for which exercises from different therapeutic approaches are available online. How likely would you use the following online exercises?

- Exercises based on cognitive behavioral therapy

Very unlikely, unlikely, neutral, likely, very likely

- Exercises based on positive psychology

Very unlikely, unlikely, neutral, likely, very likely 


\section{PERCEPTION TOWARD BLENDED CARE}

- Exercises based on Acceptance and Commitment Therapy (ACT)

Very unlikely, unlikely, neutral, likely, very likely

- Mindfulness exercises

Very unlikely, unlikely, neutral, likely, very likely

- Exercises based on schema focused therapy

Very unlikely, unlikely, neutral, likely, very likely

- Exercises from psychodynamic psychotherapy

Very unlikely, unlikely, neutral, likely, very likely

- Exercises based on interpersonal therapy.

Very unlikely, unlikely, neutral, likely, very likely

17. Imagine that you are going to work with a new blended care platform. Which preparatory activities would then be necessary?

- Obtain more information about the available online components

Totally unnecessary, unnecessary, neutral, necessary, totally necessary

- Obtain more clarity regarding legal issues/liability

Totally unnecessary, unnecessary, neutral, necessary, totally necessary

- Obtain more information about the effectiveness of the blended care program

Totally unnecessary, unnecessary, neutral, necessary, totally necessary

- Follow a training to use the blended care program

Totally unnecessary, unnecessary, neutral, necessary, totally necessary

- Providing a more secure network

Totally unnecessary, unnecessary, neutral, necessary, totally necessary

- Gather information about existing ethical/clinical guidelines regarding blended care

Totally unnecessary, unnecessary, neutral, necessary, totally necessary

- Improve my computer skills

Totally unnecessary, unnecessary, neutral, necessary, totally necessary

- Arranging better IT support

Totally unnecessary, unnecessary, neutral, necessary, totally necessary

- Ascertain whether my care organization agrees to use the blended care platform

Totally unnecessary, unnecessary, neutral, necessary, totally necessary

- Determine the associated incomes and costs of the blended care platform

Totally unnecessary, unnecessary, neutral, necessary, totally necessary

- Determine the impact on my time investment (preparation and implementation of the program).

Totally unnecessary, unnecessary, neutral, necessary, totally necessary

- Determine the perceptions of my patients toward a blended care program

Totally unnecessary, unnecessary, neutral, necessary, totally necessary

This was the end of the online survey. Thank you very much for participation. Do you have any further comments?

- Yes

- No 